Ręba Patrycja. Diabetic foot as a complication of diabetes. Journal of Education, Health and Sport. 2020;10(4):169-174. eISSN 23918306. DOI http://dx.doi.org/10.12775/JEHS.2020.10.04.019

https://apcz.umk.pl/czasopisma/index.php/JEHS/article/view/JEHS.2020.10.04.019

https://zenodo.org/record/3760210

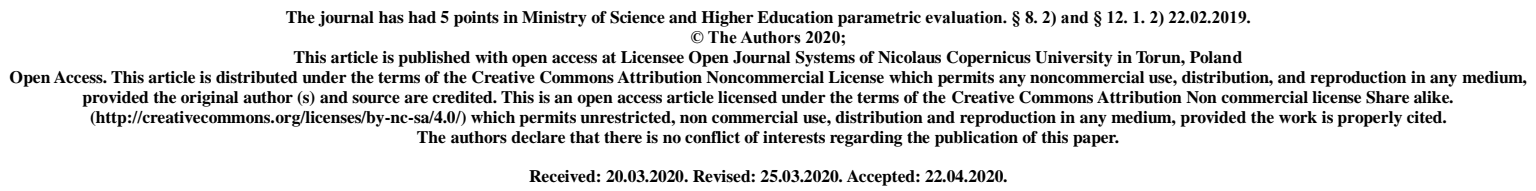

Diabetic foot as a complication of diabetes

\title{
Patrycja Ręba
}

Faculty of Medicine and Health Sciences,

Jan Kochanowski University in Kielce

\begin{abstract}
Admission

Diabetic foot is a chronic complication of diabetes. Is a shallow or deep skin ulcer. It can occur with both type 1 and type 2 diabetes. Diabetic foot can appear in anyone with diabetes. This condition is associated with all kinds of complications or pathological changes that are a direct result of diabetes. Patients also complain of ulcers, infections and neurogenic arthropathy also known as Charcot's joints.
\end{abstract}

Aim

The aim of the study is to analyze the diabetic foot as a complication of diabetes.

Material and method

Review of available literature on the subject. 


\section{Results}

Along with the diagnosis of diabetic foot, doctors classify the disease according to the Wagner classification, i.e. a 6-point scale. The division of the diabetic foot syndrome takes into account the assessment of blood supply, the size and penetration of the ulcer, as well as the severity of the infection and the occurrence of diabetic neuropathy. The first grade of diabetic foot syndrome is free of signs and symptoms of infection, as there is no infection. In the second degree, the infection is local and covers only the skin and subcutaneous tissue, without involvement of deeper tissues and without systemic symptoms. In the third degree of diabetic foot syndrome, a local infection is present without involvement of deeper tissues with erythema over $2 \mathrm{~cm}$ in diameter fascia. The fourth degree of diabetic foot syndrome is characterized severe, including local lesions in combination with systemic symptoms.

\section{Conclusions}

Diabetic foot is treated primarily by leveling diabetes and maintaining normal glycemia. In the case of large ulcers, a visit to a surgeon will be required who will develop the ulcer and recommend further action. Also, if you get an infection you will need to take by mouth antibiotic or appropriate topical preparations. Diabetic foot syndrome is just one of many complications of untreated diabetes that can lead to disability or even premature death. This should be a cautionary tale for people who disregard the need for systematic blood glucose control.

Key words: diabetic foot; diabetes

\section{Article}

Diabetic foot is a chronic complication of diabetes. Is a shallow or deep skin ulcer. It can occur with both type 1 and type 2 diabetes. The lesions are usually located on the plantar or dorsal part of the foot, most often on the backs of the fingers, heel or the heads of the metatarsal bones [1,2].

Diabetics should not have problems with noticing the first symptoms of the diabetic foot patients experience numbness and tingling in the extremities along with a decrease in sensation in the foot - especially sensation of temperature and vibration, as well as a decrease in muscle tone. The condition of the epidermis also deteriorates - the skin becomes thin, rough and breaks, and the wounds heal for a very long time or not at all. Corns, corns, calluses and cracks appear on the sole of the foot. They are often accompanied by serious sores. Bones and nails are also deformed. The critical moment is the occurrence of dark brown, black or yellow ulcers - this is a signal that tissue necrosis has started [1, 2, 3].

Diabetic foot can appear in anyone with diabetes. This condition is associated with all kinds of complications or pathological changes that are a direct result of diabetes. Patients also complain of ulcers, infections and neurogenic arthropathy also known as Charcot's joints. The two main problems that people with diabetes often face are nerve damage and poor circulation. They can lead to blisters and skin lesions. If left untreated, infection and serious complications will occur. In extreme cases, amputation of the toes or feet may be necessary. Therefore, prevention and proper care of your feet is essential. Thanks to early detection of problems, treatment and care can be used, limiting the consequences $[3,4,5]$. 
Along with the diagnosis of diabetic foot, doctors classify the disease according to the Wagner classification, i.e. a 6-point scale. Grade I is granted when a surface ulcer can be seen on the foot, which gradually develops and leads to inflammation of the skin and subcutaneous tissues. Ulceration is a break in the tissue continuity, which is characterized by cylindrical edges. Wounds located in different places on the foot can easily become bacterial superinfected. In this situation, the ulcer is red, purulent discharge and an unpleasant odor appear. The patient experiences very severe pain, the risk of amputation increases. In such a condition, the foot must undergo surgery - it is best to apply wound drainage to remove purulent contents $[5,6]$.

Diabetic foot syndrome is an infection, ulceration or destruction of the deep tissues of the foot - including bones - in patients with diabetes, as well as the presence of neurological disorders or peripheral arterial disease in the lower extremities. There are different degrees of this disease. The division of the diabetic foot syndrome takes into account the assessment of blood supply, the size and penetration of the ulcer, as well as the severity of the infection and the occurrence of diabetic neuropathy. The first grade of diabetic foot syndrome is free of signs and symptoms of infection, as there is no infection. In the second degree, the infection is local and covers only the skin and subcutaneous tissue, without involvement of deeper tissues and without systemic symptoms. It may also appear small erythema. This type of infection is classified as mild. In the third degree of diabetic foot syndrome, a local infection is present without involvement of deeper tissues with erythema over $2 \mathrm{~cm}$ in diameter. Sometimes there is also an infection involving structures deeper than the skin or subcutaneous tissue - such ailments as abscess, osteomyelitis, purulent arthritis, and fasciitis may appear. In the absence of systemic symptoms of inflammation, we are talking about a moderate infection. The fourth degree of diabetic foot syndrome is characterized severe, including local lesions in combination with systemic symptoms $[3,6,7]$.

The occurrence of diabetic foot is most often accompanied by ulceration. An ulcer is a kind of wound that you do not want to heal: the skin cracks and the underlying tissue is exposed. Diabetes negatively affects the natural wound healing process. This means that lesions and blisters that disappear quickly in healthy people can easily lead to infection in sick patients. Ulcers often appear as a result of small cuts, blisters or burns. They can also occur in people wearing mismatched shoes, appear when a pebble gets inside or a protruding element causes constant abrasions, until the place is covered with bubbles or cracks. Patients with diabetes are also sensitive to nerve damage (neuropathy) that occurs as a result of prolonged elevated blood sugar levels. Chronic neuritis can cause skin dryness, and cracks or fissures may appear on the feet. Bacteria can enter the cracked skin, causing infection. Due to the fact that damage to the nerves leads to loss of sensation in the foot, blisters and wounds that appear at the site of the prints or other paralyzed parts of the feet may go unnoticed. When the patient moves, their condition will deteriorate further, which may easily lead to bacterial infection $[1,7,8]$. blisters and wounds appearing at the site of the callus or other paralyzed parts of the feet may go unnoticed. When the patient moves, their condition will deteriorate further, which may easily lead to bacterial infection $[1,7,8]$. blisters and wounds appearing at the site of the callus or other paralyzed parts of the feet may go unnoticed. When the patient moves, their condition will deteriorate further, which may easily lead to bacterial infection [1, $7,8]$. 
In the absence of treatment, the consequences of foot ulcers can be serious. Fortunately, however, ulcers respond quickly to treatment. The first step should be to treat the ulcer to prevent infection and allow healing. The nurse will help you change the dressing regularly. You can also get a referral to a podiatrist who will remove the hard skin that prevents the ulcer from healing. If an infection occurs, your doctor may also prescribe an antibiotic. Depending on the location of the ulcer and severity, the specialist may recommend wearing special diabetic shoes or put on a stiff or plaster cast to reduce pressure and allow faster healing. In some cases, you may need to be in a hospital to allow specialized treatment, e.g. uncomplicated surgery to remove dead tissue or discharge pus. To prevent ulcers, it is very important to check and control your blood glucose regularly. You should also check your feet daily for cuts, blisters or any changes. The main cause of cuts and blisters on the feet are inadequately matched shoes. Lace-up or Velcro shoes are perfect because they allow easy adjustment of the fit $[8,9,10]$.

Neurogenic arthropathy is another condition that can adversely affect the feet of a person with diabetes as a result of nerve damage. This condition is also known as Charcot joints (Jean-Martin Charcot was a French neurologist). It weakens the bones of the foot in people with severe nerve damage. With bone weakness, micro fractures may occur, and in severe cases, joint damage may even occur. As a result of nerve damage, sensation in the feet disappears. Then the patient does not feel pain, injury or temperature changes. This means that it is likely that the patient will move normally, causing an open fracture and making the situation worse. The foot may be deformed or deformed. Distortions also increase the risk of foot ulcers. If the foot feels overheated or begins to swell after a small impact or injury, this may indicate the first signs of Charcot's joints. There may (but does not have to) be pain, redness and / or swelling appear, and when touching a sick foot, it will seem warmer than a healthy foot $[4,7,10]$.

In the early stages, when the bones are weak but not broken, the foot can be inserted into a cast to reduce damage and prevent deformation. Plaster dressing will immobilize the foot and allow it to recover. In more advanced cases, surgery may be required to adjust broken or deformed bones $[5,8]$.

A patient with diabetes complications should be under the constant care of a diabetologist as well as a professional podologist. In the treatment of diabetes, the most important thing is to maintain adequate blood glucose levels as well as normal blood pressure and cholesterol. The diabetic should also take care of the health of his feet, i.e. wear specialized footwear and insoles as well as socks - cotton and without seams. Before every putting on the shoes, you need to check if they are pebbles. Due to the reduced sensation in the foot, the patient will not feel the gravel that can stick to the skin when walking. The risk of abrasions and other mechanical injuries should be minimized, therefore it is not advisable to tighten the shoelaces and put shoes on bare feet. Patients who do not yet have blood circulation disorders should include moderate physical effort in their daily routine - to improve circulation and pancreas $[3,10]$.

Diabetic foot is treated primarily by leveling diabetes and maintaining normal glycemia. In the case of large ulcers, a visit to a surgeon will be required who will develop the ulcer and recommend further action. Also, if you get an infection you will need to take by mouth antibiotic or appropriate topical preparations $[2,4,8]$. 
A good solution in treatment is the use of specialized dressings. They help significantly accelerate the healing of changes in the course of diabetic foot. The type of dressing must be ordered by the doctor after seeing the change - an incorrectly selected dressing can harm the patient, not help. It should be remembered that the treatment of diabetic foot is definitely more difficult than its prevention. Therefore, it is worth following the rules that will avoid this disease so that you do not have to experience long and tedious therapy $[5,8,10]$.

According to the recommendations of the Polish Federation of Education in Diabetology, all patients with type 2 diabetes and adults with long-term type 1 diabetes should have basic foot tests. This is a non-invasive test that includes several elements:

1. Vibration sensing test, performed with a calibrated tuning fork or reed that creates vibration.

2. Pressure sensing test - using a monofilament that it exerts standardized pressure on the skin.

3. Examination of pain sensation - using a Neurotips needle.

4. Temperature sensing test.

5. Assessment of macrocirculation - by palpation, the doctor assesses the pulse on the dorsal artery

both feet, ankle-brachial index (ABI) test.

6. Visual assessment: deformities of the feet, skin and nails [7, 10].

The causes of the diabetic foot lie primarily in late diagnosis of diabetes. Unfortunately, it is estimated that there are about 3 million people with diabetes in Poland, of which as many as a third have no idea about their disease. Meanwhile, the treatment of ZSC is closely related to the treatment of diabetes itself, which consists in equalizing blood sugar levels. Already at the stage of diagnosis, the doctor recommends the patient to implement preventive measures in the form of special insoles, control and proper foot hygiene, as well as to fight atherosclerosis, obesity and hypertension. Advanced stages of the disease require antibiotic therapy, agents that improve blood supply to the extremities, dressings, surgery and even skin transplants. Unfortunately, poorly treated diabetic foot syndrome can lead to progressive necrosis that threatens the patient's life.

Diabetic foot syndrome is just one of many complications of untreated diabetes that can lead to disability or even premature death. This should be a warning for people who disregard the need for systematic control of blood glucose $[9,10]$. 


\section{Literature:}

1. Karnafel W., Diabetic foot syndrome. Pathogenesis, diagnostics, clinic, treatment. PZWL, Warsaw 2013.

2. Karnafel W., Wardyna K., Życińska K., Practitioner's physician's guide. Diabetic Foot. Diabetologia. Czelej Publishing House, Lublin 2008.

3. Sieradzki J., Koblik T., Diabetic foot syndrome. Via Medica, Gdańsk 2008.

4. Szkiler E. A guide to chronic wound care. Evereth, Warsaw 2014.

5. Mrozikiewicz-Rakowska B., Krasnodębski P., Jasik M., The role of a diabetologist in the prevention of diabetic foot syndrome, "Metabolic Medicine" 2013, 17 (4), 68-74.

6. Nehring P., Mrozikiewicz-Rakowska B., Risk factors for diabetic foot syndrome in patients with type 1 diabetes, "Clinical Diabetologia" 2013, 2 (5), 160-164.

7. https://www.nephrocare.pl/dla-pacjentow-strona-glowna/nerki-i-choroby-nerek/schorzeniawspolistniejace/cukrzyca/powiklania-cukrzycy-i-stopa-cukrzycowa.html [04.03.2020]

8. https://apteline.pl/artykuly/klasyfikacja-i-obraz-kliniczny-zespolu-stopy-cukrzycowej/ [03.28.2020]

9. https://www.doz.pl/czytelnia/a13824-

Stopa_cukrzycowa_8211_objawy_leczenie_i_zapobieganie_schorzeniu [04.02.2020]

10. https://www.mp.pl/cukrzyca/powiklania/66541,stopa-cukrzycowa [29.03.2020] 